\title{
Multiple spinal epidural metastases; an unexpectedly frequent finding
}

\author{
J J van der Sande, R Kröger, W Boogerd
}

\begin{abstract}
In a prospective study, patients with known malignant disease who were suspected of having a spinal epidural metastasis, had myelography which was not confined to the clinically suspected site, but included at least the whole lumbar and thoracic spinal canal. Fifty four of the 106 myelograms revealed at least one epidural metastasis. Twelve of these 54 myelograms showed two separate lesions, and four myelograms showed three separate lesions. In all 16 cases with multiple lesions at least one of the lesions was asymptomatic at the time of the diagnosis. It is concluded that multiple spinal epidural metastases are of common occurrence and occur in about one third of the cases. This finding may have important clinical implications. Examination of the spinal canal for epidural metastases should not be confined to the clinically suspected site, but should include as extensive an area as possible of the spinal canal, whatever technique is to be used.
\end{abstract}

Spinal epidural metastases are estimated to occur in about 5 to $10 \%$ of patients with malignant disease, ${ }^{1}$ and represent a common cause of serious disability, often by a permanent loss of ambulation. Therefore, the earliest possible recognition and treatment of spinal epidural metastases is of paramount importance. The medical history and a careful physical neurological examination will give an indication of the level of a spinal epidural tumour. However, spinal epidural metastases at a level unrelated to the clinical symptoms were reported to occur in $8 \%$ of the patients. ${ }^{2}$ Remarkably little attention has been paid to multiple and asymptomatic epidural metastases. Multiple epidural metastases were reported only occasionally, ${ }^{34}$ and occurred in respectively $11 \%$ and $17 \%$ of the patients, ${ }^{56}$ without further details being given. This study was undertaken to investigate the occurrence of multiple spinal epidural metastases (MSEM) prospectively.

\section{Methods}

Since at least $85 \%$ of all spinal epidural metastases occur in the thoracic or lumbar spinal canal, ${ }^{7}$ we considered visualisation of at least this area sufficient to obtain an impression of the total incidence of MSEM. One hundred and six consecutive myelograms with visualisation of at least the whole lumbar and thoracic spinal canal were therefore included in this study. These myelograms were performed with water-soluble contrast material via lumbar puncture, in patients with known malignant disease, when clinical evidence suggested an epidural lesion in the thoracic or lumbar region. Myelography was considered to be indicated when a patient developed radicular pain and/or clinical signs of radiculopathy or spinal cord or cauda equina compression, irrespective of the findings on plain radiographs and bone scan. When an obstructing lesion was found, both the upper and the lower border were visualised, if necessary, by additional cisternal puncture. In 10 of the 106 myelograms not only the lumbar and thoracic spinal canal, but also the whole cervical area could be visualised.

\section{Results}

Thirty nine $(37 \%)$ of the 106 myelograms were performed on men, $67(63 \%)$ on women. Age distribution ranged from 31 to 84 years, mean age being 53.8 years. The various sites of the primary tumours are shown in table 1 . Myelographic findings consisted of epidural metastases in 54 myelograms $(51 \%)$, degenerative abnormalities in 21 (20\%), intradural metastases in five $(5 \%)$, and no abnormalities in 26 myelograms $(25 \%)$.

Multiple spinal epidural metastases (MSEM) were demonstrated in $16(30 \%)$ of the 54 myelograms with epidural metastases. Twelve myelograms revealed two lesions, four myelograms revealed three lesions simultaneously. The characteristics of these sixteen cases are presented in table 2. Seven had breast carcinoma, and three had melanoma as the primary tumour. Interestingly, seven myelograms were performed in patients with melanoma; three revealed MSEM, three revealed single spinal epidural metastases (SSEM), and only one myelogram did not reveal metastasis, but a lumbar canal stenosis.

The symptomatic lesions occurred predominantly in the upper and middle part of the thoracic, and in the lumbosacral area. The asymptomatic lesions occurred mainly in the upper and middle thoracic area, and less frequently in the lumbosacral area (fig 1).

Comparison of MSEM ( $\mathrm{n}=16)$ and SSEM $(n=38)$ cases did not reveal a significant difference between these two groups for distribution of age, mean age and sex. The 
Table 1 Site of primary tumour in 106 cases with myelography including at least the whole lumbar and thoracic spinal canal

\begin{tabular}{|c|c|c|c|}
\hline Primary tumour & $\begin{array}{l}\text { Total } \\
\text { numbers of } \\
\text { myelograms }\end{array}$ & $\begin{array}{l}\text { Myelograms } \\
\text { with } \\
\text { epidural } \\
\text { metastases }\end{array}$ & $\begin{array}{l}\text { Myelograms } \\
\text { with } \\
\text { multiple } \\
\text { epidural } \\
\text { metastases }\end{array}$ \\
\hline $\begin{array}{l}\text { Breast } \\
\text { Lymphoma } \\
\text { Lung } \\
\text { Melanoma } \\
\text { Genito-urinary } \\
\text { Gastro-intestinal } \\
\text { Unknown primary site } \\
\text { Nasopharynx } \\
\text { Thyroid } \\
\text { Sarcoma } \\
\text { Miscellaneous }\end{array}$ & $\begin{array}{r}47 \\
12 \\
10 \\
7 \\
7 \\
6 \\
6 \\
4 \\
2 \\
2 \\
3\end{array}$ & $\begin{array}{r}29 \\
6 \\
2 \\
6 \\
2 \\
1 \\
4 \\
- \\
2 \\
2\end{array}$ & $\begin{array}{l}\frac{7}{1} \\
\frac{3}{1} \\
\frac{1}{-} \\
\frac{1}{2}\end{array}$ \\
\hline Total & 106 & 54 & 16 \\
\hline
\end{tabular}

Table 2 Characteristics of patients with multiple epidural lesions

\begin{tabular}{|c|c|c|c|c|c|c|}
\hline$\frac{N o}{17}$ & $\begin{array}{c}\begin{array}{c}\text { Age } \\
(y r)\end{array} \\
38\end{array}$ & $\begin{array}{l}\text { Sex } \\
\mathrm{F}\end{array}$ & $\begin{array}{l}\text { Primary tumour } \\
\text { Melanoma }\end{array}$ & \multicolumn{3}{|c|}{ Level of epidural lesions* } \\
\hline $\begin{array}{r}17 \\
24 \\
49 \\
60 \\
64 \\
65 \\
80 \\
92 \\
102 \\
103 \\
111 \\
117 \\
122 \\
141 \\
142 \\
155\end{array}$ & $\begin{array}{l}38 \\
84 \\
49 \\
65 \\
72 \\
73 \\
53 \\
51 \\
35 \\
53 \\
75 \\
32 \\
31 \\
55 \\
62 \\
38\end{array}$ & $\begin{array}{l}F \\
F \\
M \\
F \\
F \\
F \\
F \\
M \\
F \\
F \\
F \\
M \\
M \\
F \\
M \\
M\end{array}$ & $\begin{array}{l}\text { Melanoma } \\
\text { Breast } \\
\text { Liposarcoma } \\
\text { Breast } \\
\text { Breast } \\
\text { Breast } \\
\text { Breast } \\
\text { Chondrosarcoma parotid gland carc. } \\
\text { Breast } \\
\text { Melanoma } \\
\text { Multiple myeloma } \\
\text { Melanoma } \\
\text { Hodgkin's disease } \\
\text { Breast } \\
\text { Adenocarcinoma of unknown origin } \\
\text { Stomach }\end{array}$ & 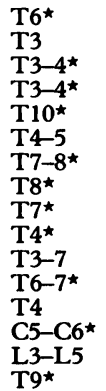 & 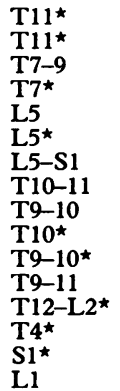 & S1 \\
\hline
\end{tabular}

«Symptomatic lesions great majority in both groups was ambulatory: $13 / 16$ of the MSEM, and $28 / 38$ of the SSEM cases. Other distant, mainly osseous, metastases were present in all MSEM cases and in 33 of the 38 SSEM cases. The five remaining cases had no distant, but regional lymph-node metastases.

A complete myelographic block was found in about one quarter of the cases in both groups. All tumours causing a complete block were symptomatic. All partial, that is, nearly complete, myelographic blocks (six of the 16 MSEM, and nine of the 38 SSEM cases) were symptomatic except one (level T4 in case 103, table 2), and although it was the largest of the three lesions in this case, it was asymptomatic. Although most cases with a complete or partial myelographic block showed clinical evidence of spinal cord or cauda equina compression, the degree of the myelographic block did not correlate with the ambulatory status: most patients with complete or partial blocks were ambulatory (8/10 of the MSEM, and $12 / 18$ of the SSEM cases).

Treatment consisted of radiotherapy in $75 \%$ of the MSEM and $71 \%$ of the SSEM cases. Seven of the $16 \mathrm{MSEM}$ cases received radiotherapy to more than one lesion, depending on the site and extent of the asymptomatic lesions. Additional chemotherapy was administered in $31 \%$ of the MSEM and $13 \%$ of the SSEM cases, whereas chemotherapy alone was administered in $12 \%$ and $11 \%$ respectively. Very few patients (one MSEM, and two SSEM cases) had surgery, in combination with radiotherapy or chemotherapy. Hormonal therapy alone was prescribed in two SSEM cases, and treatment was abandoned in one MSEM and three SSEM cases.

The clinical course revealed neurological improvement in $62 \%$ of the MSEM and 53\% of the SSEM cases, unchanged neurological condition in $25 \%$ and $34 \%$, and deterioration in $12 \%$ and $13 \%$ respectively. After a median follow up of three months mortality was higher in the MSEM (94\%) than in the SSEM group (63\%), but this difference is not significant (log rank test; $p=0 \cdot 14)$.

\section{Discussion}

Myelography with identification of the upper and lower border of the tumour is still the most widely used technique to establish the diagnosis of spinal epidural metastases. ${ }^{3}$ Spinal computed tomography (CT) can give valuable additional information, especially in identifying metastatic vertebral disease and the paraspinal extension of the tumour. CT with intrathecal contrast can also be used to visualise spinal epidural metastases, ${ }^{8}$ and may be helpful in defining the upper level of the tumour in cases with an apparent block at conventional lumbar myelography..$^{9}$ More recently, magnetic resonance imaging (MRI) was shown to be a useful technique in establishing an early diagnosis of spinal epidural metastases. ${ }^{4}$ Although MRI is generally recommended to possibly avoid a lumbar puncture, to demonstrate paravertebral tumour extension, and to 
identify additional osseous metastases, ${ }^{10-12}$ studies comparing the clinical efficacy of MRI and myelography in patients with spinal epidural metastases are scarce, ${ }^{213}$ and with conflicting results. Small epidural deposits and root compressions might be better detected with myelography. ${ }^{13}$

Finally, even when MRI is being used in cancer patients to demonstrate spinal metastases, a lumbar puncture is still necessary to obtain cerebrospinal fluid (CSF) cytology to exclude meningeal carcinomatosis as the cause of the neurological symptoms and signs.

In this prospective study the number of MSEM is remarkably high (30\%). This percentage might have been slightly higher if not only the thoracic and lumbar spinal canal would have been visualised, but also the cervical spinal canal in all cases (in this study in 10 of the 106 cases). However, only $15 \%$ of all spinal epidural metastases occur in the cervical area. ${ }^{7}$ Accordingly, the total occurrence of MSEM may not be estimated at $30 \%$, but at $35 \%$

$$
\left(30 \%+\frac{15}{85} \times \frac{96}{106} \times 30 \%\right) .
$$

Another finding in this study was the frequent occurrence of MSEM in melanoma patients. Although the numbers are small, the results suggest an occurrence of MSEM in even $50 \%$ of melanoma patients with spinal epidural metastases.

Twelve of the 16 MSEM cases in this study showed two, and four showed even three separate metastases. In all these 16 cases, at least one epidural lesion was asymptomatic. Furthermore, it was shown that the great majority of patients with spinal epidural metastases have other distant, mainly osseous, metastases as well. Accordingly, not only local treatment, but also systemic therapy should be seriously considered in patients with spinal epidural metastases.
Finally, in case of apparent failure of local radiotherapy, the presence of another, previously asymptomatic, spinal metastasis might be the cause of the neurological deterioration. For these reasons, visualisation of not only the clinically suspected site, but also as extensive an area as possible of the spinal canal, should be recommended in patients with spinal epidural metastases.

We thank Dr R Steinmetz, Dr F de Leeuw and Dr P Cohen who performed a number of myelographies, Mr AAM Hart for statistical analysis, and Miss CWessel for secretarial assistance.

1 Barron KD, Hirano A, Araki S, et al. Experiences with metastatic neoplasms involving the spinal cord. Neurology 1959;9:91-106.

2 Graus F, Krol K, Foley K. Early diagnosis of spinal epidural metastasis: correlation with clinical and radiological findings. Proc Ann Meet Am Soc Clin Oncol 1985;4:269.

3 Rodichok LD, Ruckdeschel JC, Harper GR, et al. Early Detection and Treatment of Spinal Epidural Metastases: The Role of Myelography. Ann Neurol 1986;20:696-702.

4 Sarpel S, Sarpel G, Yu E, et al. Early Diagnosis of SpinalEpidural Metastasis by Magnetic Resonance Imaging. Eancer 1987;59:1112-16.

5 Siegal T, Siegal T. Surgical Decompression of Anterior and Posterior Malignant Epidural Tumours Compressing the
Pal Spinal Cord: A prospective Study. Neurosurgery 1985;17:424-32.

6 Gilbert RW, Kim JH, Posner JB. Epidural Spinal Cord Compression from Metastatic Tumour: Diagnosis and Treatment. Ann Neurol 1978;3:40-51.

7 Törmä T. Malignant tumours of the spine and the spinal extradural space. A study based on 250 histologically verified cases. Acta Chir Scand (Suppl) 1957;225:1-176.

8 O'Rourke T, George CB, Redmond J, et al. Spinal CT scanning and CT metrizamide myelography in the detection of spinal bone and epidural metastasis. Proc Ann Meet Am Soc Clin Oncol 1985;4:7.

9 Fink IJ, Garra BS, Zabell A, et al. Computed Tomography with Metrizamine Myelography to Define the Extent of Spinal Canal Block Due to Tumour. J Comput Assist Spinal Canal Block Due

10 Kent DL, Larson EB. Magnetic Resonance Imaging of the Brain and Spine. Its Clinical Efficacy Established after the First Decade? Ann Int Med 1988;108:402-24.

11 Zimmerman RA, Bilanink LT. Imaging of Tumors of the Spinal Canal and Cord. Radiol Clin North Am 1988;26:965-1007.

12 Smoker WRK, Godersky JC, Knutzon RK, et al. The Role of MR Imaging in Evaluating Metastatic spinal Disease. AJR 1987;149:1241-8.

13 Hagenau C, Grosh W, Currie M. Wiley RG. Comparison of Spinal Magnetic Resonance Imaging and Myelography in Cancer patients. J Clin Oncol 1987;5:1663-9. 